\title{
EFEKTIVITAS BANTUAN UNTUK KORBAN BENCANA GEMPA BUMI LOMBOK
}

\author{
Sri Diantini ${ }^{1 \S}$, I Putu Eka N. Kencana ${ }^{2}$, Ni Luh Putu Suciptawati ${ }^{3}$ \\ ${ }^{1}$ Program Studi Matematika, Fakultas MIPA - Universitas Udayana [Email: niluhsridiantini@ gmail.com] \\ ${ }^{2}$ Program Studi Matematika, Fakultas MIPA - Universitas Udayana [Email: i.putu.enk@unud.ac.id] \\ ${ }^{3}$ Program Studi Matematika, Fakultas MIPA - Universitas Udayana [Email: suciptawati@unud.ac.id] \\ ${ }^{\S}$ Corresponding Author
}

\begin{abstract}
On August 2018, an earthquake occurred in North Lombok, West Nusa Tenggara which can be felt from a neighbor region such as West Lombok, Karangasem, and many others. The earthquake caused many casualties and material made many people feel sympathy for the victims of the earthquake. Therefore, many aids and donations came to the affected areas. However, the arrival of aids didn't result in similar perception among victims. The aim of this research is to analyze aid effectiveness of earthquake disaster victims in Lombok, West Nusa Tenggara. In addition, the expectation, realization, and response time of aids will be considered. This research implemented by using partial least square-structural equation modeling (PLS-SEM). This research uses six-first order latent variable, three-second order and one-third order latent variable were built by hierarchical construct model. Data were collected by using questionnaires with 5 likert scale on December 2018 that were distributed directly to 180 victims of earthquake disaster with purposive sampling method. The results show the expectation, realization, and response time regarding the aids for the victims was significant in affecting aid effectiveness and aids of earthquake disaster victims was effective.
\end{abstract}

Keywords: Aid Effectiveness, Earthquake Victims, Hierarchical Construct Model, PLS-SEM

\section{PENDAhUluaN}

Indonesia merupakan salah satu negara yang sering mengalami bencana alam. Pada bulan Agustus 2018 bencana alam gempa bumi terjadi di Pulau Lombok, Nusa Tenggara Barat (NTB). Menurut Badan Meteorologi, Klimatologi, dan Geofisika (BMKG) gempa dengan kekuatan 7,0 pada Skala Richter (SR) terjadi pada tanggal 5 Agustus 2018 berpusat di $18 \mathrm{~km}$ Barat Laut Lombok Timur, NTB yang dinyatakan sebagai gempa bumi utama serta gempa susulan berulang-ulang.

Gempa bumi yang terjadi di Pulau Lombok mengakibatkan banyak korban jiwa dan korban luka serta kerusakan bangunan yang sangat parah. Menurut Badan Nasional Penanggulangan Bencana (BNPB) korban jiwa di daerah Lombok tercatat sebanyak 457 jiwa. Kejadian gempa yang mengakibatkan banyak korban jiwa dan materi membuat banyak kalangan merasa simpati terhadap korban gempa bumi. Hal ini diketahui dari banyaknya bantuan yang diperoleh korban dari berbagai kalangan.

Dalam penelitian ini, bantuan yang diperoleh korban bencana akan dikelompokkan menjadi dua jenis, yaitu bantuan untuk kebutuhan fisiologis dan psikologis. Setiap penerima bantuan memiliki persepsi yang berbeda terhadap bantuan yang diterima. Hal ini menyebabkan peneliti ingin mengetahui persepsi korban bencana gempa bumi Lombok tentang efektivitas bantuan yang diperoleh. Salah satu metode yang dapat digunakan untuk mengukur persepsi adalah structural equation modeling (SEM).

Structural Equation Modeling (SEM) merupakan teknik analisis multivariat yang menggabungkan aspek analisis faktor dan analisis regresi, di mana analisis faktor 
diterapkan pada analisis antara variabel laten dengan indikatornya sedangkan analisis regresi diterapkan pada analisis antarvariabel laten (Hair et al, 2010). SEM terbagi menjadi dua, yaitu SEM berbasis kovarians (CB-SEM) dan SEM berbasis varians yang disebut dengan partial least square- structural equation modeling (PLS-SEM). SEM berbasis kovarians (CBSEM) digunakan untuk mengonfirmasi atau menyanggah suatu teori. Sebaliknya, SEM berbasis varians (PLS-SEM) digunakan untuk mengembangkan suatu teori dalam penelitian eksplorasi (Hair et al, 2014).

CB-SEM merupakan metode yang digolongkan kedalam metode statistika parametrik, sehingga banyak asumsi yang harus dipenuhi saat menggunakannya, seperti kenormalan, pencilan, dan data dengan jumlah besar. Pada saat data yang digunakan dalam penelitian tidak memenuhi asumsi pada CBSEM, maka PLS-SEM merupakan metode alternatif yang dapat digunakan untuk menganalisis. Hal ini disebabkan karena PLSSEM merupakan metode statistika nonparametrik yang tidak memerlukan asumsi seperti CB-SEM.

Analisis pada SEM akan membentuk dua model, yaitu model pengukuran (outer model) dan model struktural (inner model). Model pengukuran merupakan model yang menjelaskan hubungan antara variabel laten dengan indikatornya, sedangkan model struktural merupakan model yang menjelaskan hubungan antarvariabel laten.

Saat variabel laten tidak bersifat unidimensioanal, namun terlebih dahulu dijelaskan oleh variabel laten dimensinya maka model konstruk berhierarki dapat digunakan untuk memodelkan kasus demikian (Wetzels et al, 2009). Model konstruk berhierarki merupakan model persamaan struktural yang bersifat multidimensional, yaitu variabel laten yang dijelaskan terlebih dahulu oleh variabel laten dimensinya, di mana high-order construct dijelaskan oleh seluruh indikator dari low-order construct yang merupakan diemensinya.

Berdasarkan uraian di atas, penelitian ini akan menggunakan metode PLS-SEM dengan model konstruk berhierarki untuk mengetahui efektivitas bantuan yang diperoleh oleh korban bencana gempa bumi Lombok.

\section{METODE PENELITIAN}

\subsection{Teknik Pengambilan Sampel}

Teknik pengambilan sampel dalam penelitian ini menggunakan metode purposive sampling sebanyak 180 responden. Adapun responden untuk penelitian ini merupakan korban bencana alam gempa bumi Lombok yang diperoleh melalui kuesioner dengan terlebih dahulu diuji kelayakan sebelum melakukan analisis tahap lanjut

\subsection{Hipotesis Penelitian}

Penelitian ini menggunakan tiga variabel laten orde kedua (second order), yaitu (1) ekspektasi, dengan dua variabel laten orde pertama, yaitu ekspektasi fisiologis dan psikologis; (2) realisasi, dengan dua variabel laten orde pertama, yaitu realisasi fisiologis dan psikologis; dan (3) waktu tanggap, dengan dua variabel laten orde pertama, yaitu waktu tanggap fisiologis dan psikologis. Sedangkan satu variabel laten orde ketiga (third order), yaitu efektivitas.

Adapun hipotesis yang dibangun dalam penelitian ini adalah:

$\mathrm{H}_{1}$ : Ekspektasi berpengaruh terhadap efektivitas bantuan

$\mathrm{H}_{2}$ : Realisasi berpengaruh terhadap efektivitas bantuan

$\mathrm{H}_{3}$ : Waktu tanggap berpengaruh terhadap efektivitas bantuan

Model konseptual penelitian ini diperlihatkan pada Gambar 1. 


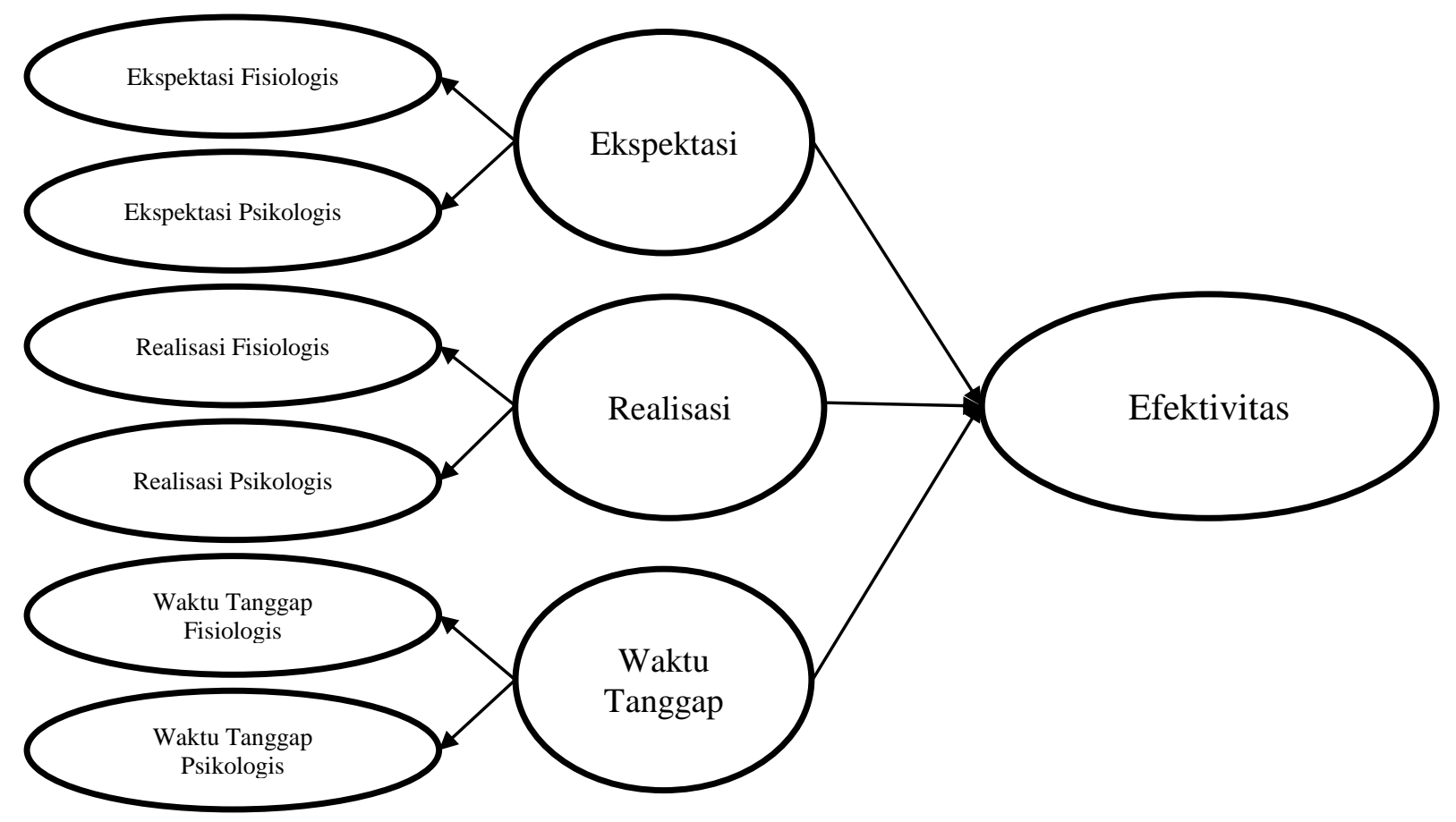

Gambar 1. Model Konseptual Penelitian

\subsection{Teknik Analisis Data}

Data yang diperoleh dalam penelitian ini dikembangkan dengan model konstruk berhierarki serta dianalisis menggunakan software SmartPLS.3 dengan langkah-langkah sebagai berikut: (1) pengembangan model teoretis; (2) pengembangan diagram jalur; (3) konversi diagram jalur ke dalam model persamaan; (4) estimasi model; (5) goodness of fit; (6) pengujian hipotesis; dan (7) interpretasi model.

\section{HASIL DAN PEMBAHASAN}

\subsection{Profil Responden}

Responden dalam penelitian ini lebih banyak perempuan yaitu sebanyak $72,22 \%$, karena laki-laki terutama pada kelompok dewasa sedang melakukan perbaikan untuk rumah darurat. Responden dengan rentang usia 30-51 tahun mendominasi, yaitu sebanyak 72,78\%. Sebanyak 45,55\% responden tidak sekolah dan sampai menempuh pendidikan sekolah dasar (SD) serta sebanyak $98,89 \%$ bekerja nonPNS. Memperhatikan hal ini, peneliti mengasumsikan penghasilan yang diperoleh masyarakat saat terjadinya bencana gempa bumi sedang tidak stabil. Sehingga sebagian besar masyarakat yang menjadi korban bencana gempa bumi di Lombok Utara memerlukan dan mengharapkan bantuan yang lebih banyak.

\subsection{Kualitas Instrumen}

Kualitas instrumen pada penelitian ini, diketahui dengan memeriksa nilai validitas dan reliabilitas variabel dengan memperhatikan nilai korelasi item dengan item total $(\rho)$ dan koefisien alpha Cronbach $(\alpha)$. Suatu item dinyatakan valid apabila $\rho>0,30$ dan suatu variabel dinyatakan reliabel apabila nilai $(\alpha \geq 0,60)$ (Hair et al, 2014). Hasil uji kualitas instrumen diperlihatkan pada Tabel 1.

Tabel 1. Kualitas Instrumen

\begin{tabular}{lrrr}
\hline \multirow{2}{*}{ Variabel Laten } & \multicolumn{2}{c}{ Jumlah Item } & $\begin{array}{r}\text { Cronbach's } \\
\text { alpha }\end{array}$ \\
\cline { 2 - 3 } & Total & Valid & 0,910 \\
\hline Ekspektasi Fisiologis & 13 & 13 & 0,871 \\
\hline Ekspektasi Psikologis & 7 & 7 & 0,893 \\
\hline Realisasi Fisiologis & 13 & 11 & 0,762 \\
\hline Realisasi Psikologis & 7 & 5 & 0,777 \\
\hline $\begin{array}{l}\text { Waktu Tanggap } \\
\text { Fisiologis }\end{array}$ & 13 & 10 & 0,774 \\
\hline $\begin{array}{l}\text { Waktu Tanggap } \\
\text { Psikologis }\end{array}$ & 7 & 5 & \\
\hline Efektivitas & 13 & 12 & 0,877 \\
\hline Sumber: data primer & & & \\
\hline
\end{tabular}

Sumber: data primer (2019), dianalisis 
Tabel 1 menunjukkan jumlah indikator valid dari total indikator yang digunakan serta nilai Cronbach's alpha seluruh variabel laten sudah memenuhi nilai yang diharapkan. Dengan demikian, model analisis pada SEM dapat dilakukan.

\subsection{Analisis Model Pengukuran}

Sebelum melakukan analisis antarvariabel laten (model struktural), terlebih dahulu akan dianalisis hubungan antara variabel laten dengan indikatornya (model pengukuran).

Pemeriksaan kualitas pengukuran dari variabel laten dengan indikator-indikator reflektif dilakukan dengan memperhatikan nilai composite reliability (CR), average variance extracted (AVE), dan outer loading. Untuk memeroleh konsistensi internal diharapkan nilai $C R \geq 0,708$ dan nilai $A V E \geq 0,50$. Selain itu, perlu diperhatikan pula nilai outer loading masing-masing indikator reflektif, diharapkan nilai outer loading $\geq 0,708$ (Hair et al, 2014).

Analisis awal menunjukkan seluruh variabel laten sudah memiliki nilai CR lebih dari batas minimal yang diharapkan, yaitu 0,708. Selanjutnya, 8 dari 10 variabel laten yang digunakan memiliki nilai AVE kurang dari 0,50. Memperhatikan hal ini, diduga variabel laten yang digunakan memiliki indikator yang tidak sesuai untuk mengukur variabel latennya. Hal ini terlihat dari nilai outer loading indikator yang digunakan masih banyak kurang dari 0,708. Dengan demikian, analisis akan diulang dengan terlebih dahulu mengeliminasi indikator dengan nilai outer loading terkecil dari variabel laten yang bersesuaian. Analisis akhir model pengukuran diringkas pada Tabel 2.

Tabel 2. Analisis Model Pengukuran

\begin{tabular}{|c|c|c|c|c|c|}
\hline $\begin{array}{c}\text { Variabel } \\
\text { Laten } \\
\text { (orde } 1,2,3 \text { ) }\end{array}$ & $\mathrm{CR}$ & AVE & Kode & Indikator & $\begin{array}{l}\text { Outer } \\
\text { loading }\end{array}$ \\
\hline \multirow{4}{*}{$\begin{array}{l}\text { (1) } \\
\text { Ekspektasi } \\
\text { Fisiologis }\end{array}$} & \multirow{6}{*}{0,902} & \multirow{6}{*}{0,607} & EF3 & Bantuan peralatan memasak & 0,654 \\
\hline & & & EF8 & Bantuan pakaian & 0,725 \\
\hline & & & EF9 & Bantuan selimut & 0,819 \\
\hline & & & EF11 & Keberadaan WC darurat di tempat pengungsian & 0,740 \\
\hline \multirow{2}{*}{$R^{2}=0,931$} & & & EF12 & Tenda untuk seluruh korban & 0,852 \\
\hline & & & EF13 & Alas tidur untuk seluruh korban & 0,862 \\
\hline \multirow{6}{*}{$\begin{array}{l}\text { Ekspektasi } \\
\text { Psikologis } \\
R^{2}=0,718\end{array}$} & \multirow{6}{*}{0,877} & \multirow{6}{*}{0,545} & EP2 & Bantuan mainan anak-anak & 0,831 \\
\hline & & & EP3 & $\begin{array}{l}\text { Kedatangan relawan untuk mengajak anak-anak } \\
\text { bermain }\end{array}$ & 0,802 \\
\hline & & & EP4 & Kunjungan kepala pemerintahan & 0,614 \\
\hline & & & EP5 & Kunjungan pemuka/tokoh agama & 0,695 \\
\hline & & & EP6 & Penyediaan tempat khusus untuk ibadah & 0,767 \\
\hline & & & EP7 & $\begin{array}{l}\text { Saya berpendapat keberadaan tenda khusus bagi } \\
\text { suami istri diperlukan }\end{array}$ & 0,700 \\
\hline \multirow{6}{*}{$\begin{array}{l}\text { Realisasi } \\
\text { Fisiologis } \\
R^{2}=0,907\end{array}$} & \multirow{6}{*}{0,905} & \multirow{6}{*}{0,616} & RF1 & Bantuan makanan untuk keluarga & 0,858 \\
\hline & & & RF2 & Bantuan sembako & 0,829 \\
\hline & & & RF4 & Bantuan air minum & 0,820 \\
\hline & & & RF5 & Kedatangan PMI dan relawan medis & 0,795 \\
\hline & & & RF6 & Bantuan ambulans yang disediakan & 0,704 \\
\hline & & & RF12 & Tenda untuk seluruh korban & 0,686 \\
\hline \multirow{5}{*}{$\begin{array}{l}\text { Realisasi } \\
\text { Psikologis } \\
R^{2}=0,663\end{array}$} & \multirow{5}{*}{0,858} & \multirow{5}{*}{0,605} & RP2 & Bantuan mainan anak-anak & 0,843 \\
\hline & & & RP3 & Kedatangan relawan untuk mengajak anak-anak & 0,891 \\
\hline & & & & bermain & \\
\hline & & & RP4 & Kunjungan kepala pemerintahan & 0,638 \\
\hline & & & RP5 & Kunjungan pemuka/tokoh agama & 0,713 \\
\hline Waktu & \multirow{4}{*}{0,861} & \multirow{4}{*}{0,556} & WF1 & Bantuan makanan untuk keluarga & 0,759 \\
\hline Tanggap & & & WF2 & Bantuan sembako & 0,760 \\
\hline \multirow[t]{2}{*}{ Fisiologis } & & & WF4 & Bantuan air minum & 0,658 \\
\hline & & & WF12 & Tenda untuk seluruh korban & 0,842 \\
\hline$R^{2}=0,526$ & & & WF13 & Alas tidur untuk seluruh korban & 0,679 \\
\hline
\end{tabular}




\begin{tabular}{|c|c|c|c|c|c|}
\hline & & & WP2 & Bantuan mainan anak-anak & 0,688 \\
\hline $\begin{array}{l}\text { Waktu } \\
\text { Tanggap }\end{array}$ & & & WP3 & $\begin{array}{l}\text { Kedatangan relawan untuk mengajak anak-anak } \\
\text { bermain }\end{array}$ & 0,846 \\
\hline Psikologis & 0,886 & 0,611 & WP4 & Kunjungan kepala pemerintahan & 0,760 \\
\hline & & & WP5 & Kunjungan pemuka/tokoh agama & 0,884 \\
\hline$R^{2}=0,879$ & & & WP6 & Penyediaan tempat khusus untuk ibadah & 0,691 \\
\hline \multirow{7}{*}{$\begin{array}{l}\text { (2) } \\
\text { Ekspektasi }\end{array}$} & \multirow{7}{*}{0,915} & \multirow{7}{*}{0,608} & EF8 & Bantuan pakaian & 0,737 \\
\hline & & & EF9 & Bantuan selimut & 0,807 \\
\hline & & & EF11 & Keberadaan WC darurat di tempat pengungsian & 0,743 \\
\hline & & & EF12 & Tenda untuk seluruh korban & 0,823 \\
\hline & & & EF13 & Alas tidur untuk seluruh korban & 0,804 \\
\hline & & & EP2 & Bantuan mainan anak-anak & 0,830 \\
\hline & & & EP3 & $\begin{array}{l}\text { Kedatangan relawan untuk mengajak anak-anak } \\
\text { bermain }\end{array}$ & 0,706 \\
\hline \multirow{7}{*}{ Realisasi } & \multirow{7}{*}{0,913} & \multirow{7}{*}{0,600} & RF1 & Bantuan makanan untuk keluarga & 0,832 \\
\hline & & & RF2 & Bantuan sembako & 0,779 \\
\hline & & & RF4 & Bantuan air minum & 0,754 \\
\hline & & & RF5 & Kedatangan PMI dan relawan medis & 0,775 \\
\hline & & & RF12 & Tenda untuk seluruh korban & 0,731 \\
\hline & & & $\mathrm{RP} 2$ & Bantuan mainan anak-anak & 0,733 \\
\hline & & & RP3 & $\begin{array}{l}\text { Kedatangan relawan untuk mengajak anak-anak } \\
\text { bermain }\end{array}$ & 0,816 \\
\hline \multirow{4}{*}{$\begin{array}{l}\text { Waktu } \\
\text { Tanggap }\end{array}$} & \multirow{4}{*}{0,879} & \multirow{4}{*}{0,645} & WF12 & Tenda untuk seluruh korban & 0,761 \\
\hline & & & WP2 & Bantuan mainan anak-anak & 0,771 \\
\hline & & & WP3 & $\begin{array}{l}\text { Kedatangan relawan untuk mengajak anak-anak } \\
\text { bermain }\end{array}$ & 0,849 \\
\hline & & & WP5 & Kunjungan pemuka/tokoh agama & 0,828 \\
\hline \multirow{5}{*}{$\begin{array}{l}\text { (3) } \\
\text { Efektivitas }\end{array}$} & \multirow{8}{*}{0,921} & \multirow{8}{*}{0,746} & EvF1 & Bantuan makanan untuk keluarga & 0,663 \\
\hline & & & EvF3 & Bantuan untuk kebutuhan nauangan & 0,710 \\
\hline & & & EvF5 & Bantuan pakaian & 0,702 \\
\hline & & & EvP1 & Bantuan mainan anak-anak & 0,699 \\
\hline & & & EvP2 & Kunjungan relawan untuk menghibur anak-anak & 0,809 \\
\hline \multirow[t]{3}{*}{$R^{2}=0,630$} & & & EvP3 & Kunjungan kepala pemerintahan & 0,740 \\
\hline & & & EvP4 & Kunjungan pemuka/tokoh agama & 0,717 \\
\hline & & & EvP5 & Penyediaan tempat khusus untuk ibadah & 0,770 \\
\hline
\end{tabular}

Sumber: data primer (2019), dianalisis

Tabel 2 menunjukkan nilai $\mathrm{CR}$ dan AVE seluruh variabel laten sudah lebih dari 0,708 dan 0,50. Selanjutnya, masih terdapat beberapa indikator dengan nilai outer loading kurang dari 0,708, meskipun demikian seluruh indikator pada Tabel 2 akan tetap dipertahankan memperhatikan nilai $\mathrm{CR}$ dan AVE sudah terpenuhi.

Memperhatikan dua indikator dengan nilai outer loading tertinggi pada variabel laten ekspektasi adalah EF12 dan EP2. Hal ini menunjukkan harapan korban terhadap bantuan paling tinggi adalah bantuan tenda dan mainan anak-anak. Namun, dua indikator dengan nilai outer loading tertinggi pada variabel laten realisasi adalah RF1 dan RP3. Hal ini menunjukkan bahwa, realisasi bantuan yang dirasakan korban paling tinggi adalah bantuan makanan dan kedatangan relawan ke tempat pengungsian. Selanjutnya, dua indikator dengan nilai outer loading tertinggi pada variabel laten waktu tanggap adalah WP3 dan WP5. Hal ini menunjukkan bahwa, bantuan yang diperoleh korban sesuai dengan waktu yang dibutuhkan adalah kedatangan relawan ke tempat pengungsian dan kunjungan tokoh agama.

Dari uraian tersebut menunjukkan bahwa, bantuan yang diperoleh paling tinggi tidak sesuai dengan bantuan yang paling diharapankan korban serta waktu diperolehnya bantuan yang paling diharapkan tidak tepat waktu. Hal ini menunjukkan bahwa bantuan yang diperoleh belum mampu memenuhi harapan korban serta 
diterimanya bantuan dirasakan belum tepat waktu.

Hasil tersebut mengacu pada Sophie et al, (2011) yang menyatakan bahwa bantuan yang diperoleh lebih ditentukan oleh pihak pemberi bantuan, baik dari segi prioritas dan preferensi alokasi bantuan. Sehingga bantuan yang diperoleh tidak sesuai dengan harapan penerima bantuan yang bersangkutan. Ini diperjelas oleh penelitian Elayah (2016) yang menyimpulkan bahwa masalah sebagian besar donatur masih mendasarkan bantuan yang diberikan pada berbagai target dan kepentingan diri sendiri termasuk politik, strategis, komersil, budaya dan agama.

Penelitian Felayati (2016) juga menunjukkan permasalahan birokrasi, korupsi dan kurangnya informasi dalam persebaran bantuan luar negeri untuk tsunami Aceh tahun
2004 mengakibatkan bantuan tersebut menjadi tidak tepat sasaran serta kurang efektif dalam mencapai tujuannya.

Secara eksplisit, dua indikator dengan nilai outer loading tertinggi pada variabel laten efektivitas adalah EvP2 dan EvP5. Hal ini menunjukkan bahwa, korban bencana merasakan bantuan yang lebih efektif adalah kunjungan relawan dan penyediaan tempat khusus untuk ibadah.

\subsection{Analisis Model Struktural}

Setelah analisis model pengukuran dianggap cukup, maka tahap selanjutnya adalah melakukan analisis model struktural. Analisis model struktural dilakukan dengan metode resampling pada software SmartPLS3 dengan subsampel sebanyak 500. Hasil analisis model struktural diperlihatkan pada Tabel 3.

Tabel 3. Analisis Model Struktural

\begin{tabular}{lrrr}
\hline & Koefisien Jalur & t-statistik & $p$-values \\
\hline Ekspektasi -> Ekspektasi Fisiologis & 0,965 & 109,023 & 0,000 \\
\hline Ekspektasi -> Ekspektasi Psikologis & 0,848 & 25,199 & 0,000 \\
\hline Realisasi -> Realisasi Fisiologis & 0,953 & 116,401 & 0,000 \\
\hline Realisasi -> Realisasi Psikologis & 0,813 & 31,773 & 0,000 \\
\hline Waktu Tanggap -> Waktu Tanggap Fisiologis & 0,729 & 17,025 & 0,000 \\
\hline Waktu Tanggap -> Waktu Tanggap Psikologis & 0,934 & 90,989 & 0,000 \\
\hline Ekspektasi -> Efektivitas & $-0,100$ & 2,130 & 0,034 \\
\hline Realisasi -> Efektivitas & 0,545 & 5,687 & 0,000 \\
\hline Waktu Tanggap -> Efektivitas & 0,330 & 3,418 & 0,001 \\
\hline Sumber: data primer (2019), dianalisis & & &
\end{tabular}

Tabel 3 menunjukkan bahwa, efektivitas bantuan yang diperoleh korban bencana secara signifikan dipengaruhi oleh ekspektasi korban terhadap bantuan, realisasi bantuan dan waktu tanggap bantuan dengan taraf nyata $5 \%$.

Memperhatikan nilai koefisien jalur ekspektasi saat memengaruhi efektivitas bantuan memiliki nilai sebesar-0,100. Hal ini menunjukkan bahwa ekspektasi memengaruhi efektivitas bantuan secara negatif, di mana saat ekspektasi korban terhadap bantuan meningkat satu satuan, mengakibatkan efektivitas bantuan menurun sebesar 0,100 satuan. Variabel realisasi memiliki nilai koefisien jalur sebesar 0,545 yang menunjukkan bahwa mmeningkatnya realisasi bantuan satu satuan mengakibatkan efektivitas bantuan meningkat sebesar 0,545 satuan. Selanjutnya, variabel waktu tanggap memiliki nilai koefisien jalur sebesar 0,330 yang menunjukkan bahwa meningkatnya waktu tanggap bantuan satu satuan mengakibatkan efektivitas bantuan meningkat 0,330 satuan.

Dari uraian paragraph terakhir, menunjukkan bahwa realisasi bantuan yang paling memengaruhi efektivitas bantuan untuk korban bencana gempa bumi Lombok.

\section{KESIMPULAN DAN SARAN}

\subsection{Kesimpulan}

Penelitian ini menyimpulkan bahwa efektivitas bantuan untuk korban bencana gempa bumi Lombok cukup efektif yang secara 
signifikan dipengaruhi oleh ketiga variabel laten eksogen (ekspektasi, realisasi, dan waktu tanggap) serta mampu menjelaskan efektivitas bantuan sebesar 63\% sisanya dijelaskan oleh variabel lain yang tidak dimasukkan dalam model.

\subsection{Saran}

1. Memperhatikan variabel ekspektasi, realisasi, dan waktu tanggap menjelaskan efektivitas bantuan sebesar 63\% peneliti menyarankan untuk mencari variabel lain yang mungkin memengaruhi efektivitas bantuan seperti manfaat bantuan yang dirasakan korban.

2. Peneliti menyarankan agar pemberi bantuan lebih memahami bantuan yang harapkan oleh korban bencana gempa bumi Lombok maupun bencana yang terjadi di daerah lain agar penyaluran bantuan menjadi lebih efektif.

3. Bagi pendistribusi bantuan agar lebih meningkatkan ketepatan waktu dalam mendistribusikan bantuan kepada korban bencana gempa bumi Lombok, sehingga bantuan yang diperoleh lebih tepat waktu.

\section{DAFTAR PUSTAKA}

Elayah, M. (2016). Lack of Foreign Aid Effectiveness in Developing Countries Between a Hammer and an Anvil. Contemporary Arab Affairs, 9(1), 82-99.

Felayati, R. A. (2016). Efektivitas Bantuan Luar Negeri di Aceh Selama 2004-2010 Setelah Tsunami Samudra Hindia tahun 2004. Jurnal Hubungan Internasional, 9(1), 3148.

Hair.Jr, J. F., Hult, G. T. M., Ringle, C. M., \& Sarsfedt, M. (2014). A Primer On Partial Least Squares Structural Equation Modeling (PLS-SEM). Los Angeles: SAGE.

Hair Jr, J. F., Black, W. C., Babin, B. J., \& Anderson, R. E. (2010). Multivariate Data Analysis (7th ed.). New Jersey: Pearson Prentice Hall.

Sophie, A., Boitreaud, R., \& Wagner, N. (2011). Natural Disaster , Conflict and Aid Allocation. Geneva.

Wetzels, M., Odekerken-schröder, G., \& Oppen, C. van. (2009). Using PLS Path Modeling for Assessing Hierarchical Construct Models. Mis Quarterly, 33(1), 177-195. 